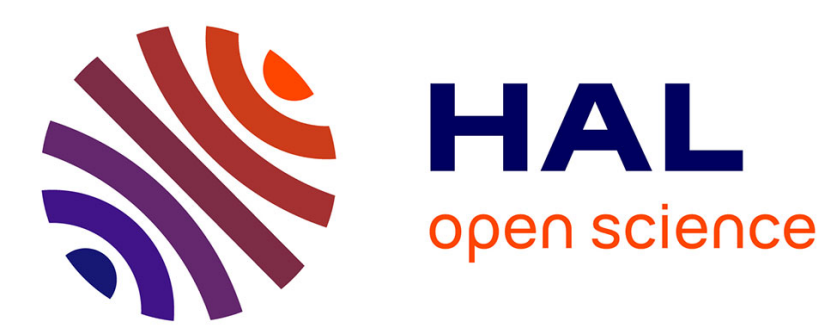

\title{
SMALL PARTICLES-DYNAMIC PROPERTIES OF LATTICEPHONONS IN SMALL PARTICLES
}

\author{
H. Baltes
}

\section{To cite this version:}

H. Baltes. SMALL PARTICLES-DYNAMIC PROPERTIES OF LATTICEPHONONS IN

SMALL PARTICLES. Journal de Physique Colloques, 1977, 38 (C2), pp.C2-151-C2-156. 10.1051/jphyscol:1977231 . jpa-00217070

\section{HAL Id: jpa-00217070 https://hal.science/jpa-00217070}

Submitted on 1 Jan 1977

HAL is a multi-disciplinary open access archive for the deposit and dissemination of scientific research documents, whether they are published or not. The documents may come from teaching and research institutions in France or abroad, or from public or private research centers.
L'archive ouverte pluridisciplinaire HAL, est destinée au dépôt et à la diffusion de documents scientifiques de niveau recherche, publiés ou non, émanant des établissements d'enseignement et de recherche français ou étrangers, des laboratoires publics ou privés. 


\title{
PHONONS IN SMALL PARTICLES (*)
}

\author{
H. P. BALTES \\ Zentrale Forschung und Entwicklung \\ LGZ Landis \& Gyr Zug AG \\ CH-6301 Zug, Switzerland
}

\begin{abstract}
Résumé. - Nous présentons une revue des théories et expériences des phonons dans les petits cristaux. En premier lieu, nous considérons les modes acoustiques et la capacité calorifique correspondante. Nous discutons aussi brièvement les vibrations optiques ainsi que l'absorption et l'émission dans l'infrarouge lointain.
\end{abstract}

\begin{abstract}
Theories and experiments on phonons in small solid particles are reviewed. Acoustical modes and the corresponding vibrational specific heat are emphasized. Optical modes and the pertinent far-infrared properties are presented as well.
\end{abstract}

1. Introduction. - Apart from a few important early contributions [1-8], the physical properties of small solid particles have been investigated in detail only during the past fifteen years. The more general field of the physics of finite systems includes aspects of not only solid state physics, but also general thermodynamics and statistical physics, quantum electrodynamics, and nuclear physics. Some current investigations are listed below. The items indicated by $*$ are presented in the subsequent sections in more detail.

THEORY. - (i) Non-relativistic perfect quantumgases. - Thermodynamic equation of state [9-11]. Bose-Einstein condensation [12, 13]. Poincarécyles [14].

(ii) Quantum-electrodynamics. - Spectral and total energy of thermal radiation in lossless small cavities [15-19]. Coherence [14, 20, 21] and related radiation corrections [22] and material effects [23]. Radiative heat transfer between closely spaced bodies [24] and the three-dimensional Casimireffect $[25,26]$.

(iii) Heavy nuclei. - Level statistics [27-29]. Surface and shape energy [30-32]. Shell correction and fission barrier [33-35].

(iv) Solid particles: electrons. - Specific heat and paramagnetism [5, 36-38]. Electric polarizability and optical absorption [1, 2, 39-45]. Spin resonance [46-49].

(v) Solid particles: acoustical phonons *. Refined mode density and specific heat $[6,50-55]$. Lattice dynamics of surface modes [56-62] and

(*) Adapted from an invited paper presented at the International Meeting on the Small Particles and Inorganic Clusters, September 13-17, 1976, Université Claude Bernard, Lyon, France. edge modes $[63,64]$. Quantum size effects $[3,4$, 65-68].

(vi) Solid particles: optical phonons *. - Optical properties of spherical $[7,69-74]$ and cubeshaped [75-77] microcrystals. Lattice dynamics of surface modes [55-62].

(vii) Phase transitions. - Heisenberg [78-80] and Ising $[81,82]$ spin systems. Superconductivity [8389].

EXPERIMENTS. - (i) Photons. - Fluorescence lifetime [90]. Radiative transfer [91]. Casimir effect [92],

(ii) Heavy nuclei. - Data on nuclear masses [30, 93] and fission barrier [35, 94].

(iii) Solid particles: electronic effects. Magnetic susceptibility [95, 96].. Electrical polarization $[97,98]$. Optical and U.V. absorption [99-102]. Far-infrared absorption [103, 104]. Spin resonance [96, 105-110]. Tunelling [111].

(iv) Solid particles: acoustical phonons * Specific heat of metals $[112,113]$ and dielectrics $[6$, 114]. Mössbauer-spectroscopy [115]. Neutron scattering [116].

(v) Solid particles: optical phonons *. - Farinfrared transmission [75, 117-125] and emission [126, 127].

(vi) Solid particles : thermodynamics. - Vapour pressure [128] and melting temperature [129] of metal grains.

The case of heavy nuclei is included in the above list since concepts of nuclear theory [27-35] have been applied to solid particles $[36,37,39,66]$. The photon gas in a small enclosure is the only non-interacting finite system and henceforth allows the study of pure size-effects. The case of the bounded photon gas was reviewed recently [130, 131]. A comprehensive report on the underlying 
mathematical problem of the distribution of the eigenvalues of the wave equation in finite domains is available as well [132].

2. Acoustical phonons. - Debye's $T^{3}$-law [133] for the low-temperature vibrational specific heat was the first classical law of bulk solid state physics that was called in question by a quantum size effect : Planck [3] and Schaefer [4] predicted that the $T^{3}$-law would break down at least for temperatures so low and particles so small that only the fundamental mode of frequency $\omega_{1}$ is appreciably excited as compared to the higher modes $\omega_{n}>\ldots>\omega_{2}>\omega_{1}$. Thus not only the condition $T \ll \theta$ with $\theta$ denoting the (bulk) Debye temperature, but also the restriction

$$
T \gg \theta_{0}=\hbar \omega_{2} / k=\theta /(3 N)^{1 / 3}
$$

with $N$ denoting the number of atoms is required for the validity of Debye's law. The vibrational specific heat is henceforth subject to the following three regimes:

(i) Single-mode regime $\theta<T \ll \theta_{0}$ with the Planck-Schaefer specific heat proprotional to $T^{2} \exp \left(-\hbar \omega_{1} / k T\right)$.

(ii) Debye regime $\theta_{0} \ll T \ll \theta$.

(iii) Dulong-Petit regime $\theta \ll T<T_{\text {meltng point }}$.

The regime (i) is observed at reasonably high temperatures $T \ll \theta_{0}$ for not too small $\theta_{0}$, say $\theta_{0} \gtrsim \theta / 5$ or $N \leq 50$, i.e. for microclusters.

Intermediate between (i) and (ii) is the case of small particles with $10^{2} \leq N \leq 10^{6}$ at sufficiently low temperatures $\theta_{0} \leq T \ll \theta$. Two different approaches are, in principle, possible here: The quantum-size approach that leads to the specific heat proportional to

$$
\frac{d}{\mathrm{~d} T} \sum_{n=1}^{3 N-3} \hbar \omega_{n}\left[\exp \left(\hbar \omega_{n} / k T\right)-1\right]^{-1}
$$

and the quasi-continuum approach feasible for not too small particles leading to

$$
\frac{d}{\mathrm{~d} T} \int \mathrm{d} \omega D(\omega) \hbar \omega[\exp (\hbar \omega / k T)-1]^{-1}
$$

with $D(\omega)$ denoting the improved mode density that accounts for size-, surface-, and shape-effects.

2.1 WEYL'S PROBLEM. - By Weyl's problem we understand the problem of calculating the eigenvalue distribution for the wave equation [132]. Weyl's considered three different types of boundary value problems :

(i) Scalar problem $\left(\nabla^{2}+k^{2}\right) u=0$ related to the perfect quantum gas by virtue of $k=\sqrt{2 m \varepsilon} / \hbar$, $\varepsilon=$ energy, and to acoustic resonators by virtue of $k=\omega / v, v=$ sound velocity.

(ii) Electrodynamic problem $\left(\nabla^{2}+k^{2}\right) \mathbf{E}=0$, $\operatorname{div} \mathbf{E}=0, k=\omega / c$, fundamental to quantumelectrodynamics in a finite box. (iii) Elastic problem [134]

$$
\left.\begin{array}{c}
\left(\Delta^{*}+\omega^{2}\right) \mathbf{u}=0, \\
\Delta^{*} \equiv A \operatorname{grad} \operatorname{div}+B \nabla^{2}, \\
v_{\mathrm{t}}=B^{1 / 2}, v_{1}=(A+B)^{1 / 2}
\end{array}\right\}
$$

relevant for the acoustical phonons in the elastic continuum model. Only Weyl's non-physical boundary-condition $\operatorname{div} \mathbf{u}=\mathbf{0}$ allows the separation into transverse modes with velocity $v_{\mathrm{t}}$ and longitudinal modes with velocity $v_{1}$ in a finite domain. Clamped boundaries with $\mathbf{u}=0$ as well as stress-free boundaries with

$$
\sum_{i}\left[\delta_{k t}(A-B) \operatorname{div} \mathbf{u}+B\left(\partial_{l} u_{k}+\partial_{k} u_{i}\right)\right]=\mathbf{0}
$$

and the intermediate case of contact boundaries lead to the scrambling of $\mathrm{t}$ - and 1-bulk modes as well as to the Raleigh-modes that are localized near the surface. Only in the limit of large volume $V$ are the boundary conditions immaterial : Weyl's theorem asserts that

$$
D(\omega) \sim \frac{V \omega^{2}}{2 \pi^{2}}\left(2 v_{\mathrm{t}}^{-3}+v_{\mathrm{l}}^{-3}\right)
$$

as $V \rightarrow \infty$ irrespective of the shape of the domain.

2.2 REFINEMENTS OF WEYL'S THEOREM. Since the days of Weyl, much effort has been spent on establishing asymptotic expansions for the mode density where Weyl's theorem provides the leading term. The problem in question is largely solved for the scalar and electromagnetic problems (see Ref. [132] for a review), but only the first-order correction or surface-term is known for the elastic problem (see Section 2.3). As an illustrative example we present here the most simple case of the scalar problem for the cube-shaped domain (edge length $L)$ with Dirichlet $(u=0)$ or Neumann $(\partial u / \partial n=0)$ boundary conditions, where the complete expansion is known [34]:

$$
\begin{aligned}
D(k) & =\frac{1}{8} \sum_{n_{1}, n_{2}, n_{3}=-\infty} \delta\left(k-\frac{\pi}{L}\left(n_{1}^{2}+n_{2}^{2}+n_{3}{ }^{2}\right)^{1 / 2}\right) \\
& \pm \frac{3}{8} \sum_{n_{1}, n_{2}=-\infty}^{+\infty} \delta\left(k-\frac{\pi}{L}\left(n_{1}^{2}+n_{2}^{2}\right)^{1 / 2}\right) \\
& +\frac{3}{8} \sum_{n_{1}=-\infty}^{+\infty} \delta\left(k-\frac{\pi}{L}\left|n_{1}\right|\right) \\
& \pm \frac{1}{8} \delta(k) \\
& =\frac{L^{3} k^{2}}{2 \pi^{2}}+\frac{L^{3} k^{2}}{2 \pi^{2}} \sum_{n_{1}, n_{2}, n_{3}}^{\prime} \frac{\sin \left(2 k L\left(n_{1}^{2}+n_{2}^{2}+n_{3}^{2}\right)^{1 / 2}\right)}{2 k L\left(n_{1}^{2}+n_{2}^{2}+n_{3}^{2}\right)^{1 / 2}} \\
& \pm \frac{3 L^{2} k}{4 \pi} \pm \frac{3 L^{2} k}{4 \pi} \sum_{n_{1}, n_{2}}^{\prime} J_{0}\left(2 k L\left(n_{1}^{2}+n_{2}^{2}\right)^{1 / 2}\right) \\
& +\frac{3 L}{4 \pi}+\frac{3 L}{4 \pi} \sum_{n_{1}}^{\prime} \cos \left(2 k L n_{1}\right) \\
& \pm \frac{1}{8} \delta(k) .
\end{aligned}
$$


Here, the primes indicate that the terms corresponding to $N_{i}=0$ for all occuring $i$ are omitted in the summation. The negative signs apply in the case of clamped surface (Dirichlet) and the positive signs in the case of free surface (Neumann). The monotonic volume-, surface-, edge-, and corner-correction terms are sufficient in the quasi-continuum regime, whereas the oscillatory terms (sums $\Sigma^{\prime}$ ) are required in addition in the quantum-size regime. We point out that the above corrections of Weyl's asymptotic limit $L^{3} k^{2} / 2 \pi^{2}$ are due to the refined counting of bulk modes and not to localized physical surface modes.

2.3 FREE PARTICLES. - From the above scalar result, we would suppose that particles with free surfaces in the quasi-continuum regime show an enhancement of the acoustical mode density and low-temperature specific heat together with the corresponding decrease of the Debye-temperature. This is indeed observed in neutron scattering [116] as well as calorimetric $[6,114]$ and Mössbauer [115] measurements. The relative decrease of the Debyetemperature is proportional to $S N^{-1 / 3}$, where $S$ denotes the surface area of the grains [135].

Results of the type (7) suggested the following scalar model [8] mode density for not too small particles,

$$
D(\omega)=\frac{V \omega^{2}}{2 \pi^{2}} v_{3}^{-3}+\frac{S \omega}{8 \pi} v_{2}^{-2}+\frac{\Lambda \omega}{4 \pi} v_{1}^{-1}
$$

with the effective sound velocities [8]

$$
v_{n}^{-n}=2 v_{\mathrm{t}}^{-n}+v_{1}^{-n}, n=3,2,1
$$

and some effective length $\Lambda$ accounting for edgeand curvature-effects. Only $v_{3}^{-3}=2 v_{1}^{-3}+v_{1}^{-3}$ is physically correct in the sense of the full elastic problem. The correct value of $v_{2}^{-2}$ was determined in terms of elastic continuum $[50,51]$ theory accounting for the correct boundary condition (5) and lattice dynamics [52-54]. It reads

$$
v_{2}^{-2}=\frac{2 v_{\mathrm{t}}^{4}-3 v_{\mathrm{t}}^{2} v_{1}^{2}+3 v_{1}^{4}}{v_{\mathrm{t}}^{2} v_{1}^{2}\left(v_{1}^{2}-v_{\mathrm{t}}^{2}\right)}
$$

a result that reflects the mode scrambling effect due to the finite size. The low-temperature heat capacity thus reads

$$
C=C_{\text {Debye }}+3 \pi \zeta(3) \frac{K^{3}}{h^{2}} \frac{S T^{2}}{v_{2}^{2}}+\mathrm{O}\left(V T^{1 / 3}\right) .
$$

Iosilevskii [53] points out that the above surfaceterm stems from the correct thermodynamic density of states of the bulk modes rather than from the localized surface-modes. A behaviour of the type $C-C_{\text {Debye }}=$ const $T^{2}$ is indeed observed $[114,116]$, but the measured constant is often a few times larger than expected from theory.

Unfortunately, the correct value of the parameter $v_{1}^{-1}$ in the elastic model $(4,5)$ is unknown hitherto.
Localized edge modes, however, are studied currently [63, 64].

A result analogous to $(10)$ is known for clamped surfaces [50-52], but not for the physically more interesting case of contact surfaces (e.g. small particles in contact with matrix material). In the spirit of the scalar model, the contact-problem would lead to the surface term proportional to

$$
S T^{2}\left(v_{\mathrm{A}}^{-2}-v_{\mathrm{B}}^{-2}\right)\left(\mu_{\mathrm{A}}-\mu_{\mathrm{B}}\right)\left(\mu_{\mathrm{A}}+\mu_{\mathrm{B}}\right)^{-1}
$$

with the sound velocities $v_{A}, v_{B}$ and the elastic constants $\mu_{\mathrm{A}}, \mu_{\mathrm{B}}$ of the two materials $\mathrm{A}$ and $\mathrm{B}$.

2.4 FREE SPHERES. - The quasi-continuum approach leads to the mode density

$$
D(\omega)=\frac{2 \omega^{2} R^{3}}{3 \pi v_{3}^{3}}+\frac{\omega R^{2}}{2 v_{2}^{2}}+\mathrm{O}(R)
$$

with $v_{3}$ and $v_{2}$ as given in (9) and (10), respectively, and to the corresponding specific heat of the type (11). The quantum size approach $[66,68]$ in the spirit of Montroll's model [8] starts from

$$
D(\omega)=\sum_{i, s} \delta\left(\omega-\omega_{l s}\right), \omega_{l s}=v a_{i s}^{\prime} R^{-1}
$$

with $a_{l s}$ denoting the zeros of the derivative of the spherical Bessel function $j_{l}$ with weight $(2 l+1)$ and $v$ denoting some effective sound velocity (adjustable parameter). The corresponding specific heat is of the type (2) with summation over the Bessel zeros until the total number $3(N-1)$ of vibrational degrees of freedom is exhausted. Such an exponential sum over discrete resonances is able to account for the non-quadratic specific heat enhancement observed for ultra-fine particles $[112,113]$ at low temperatures (see Fig. 1).

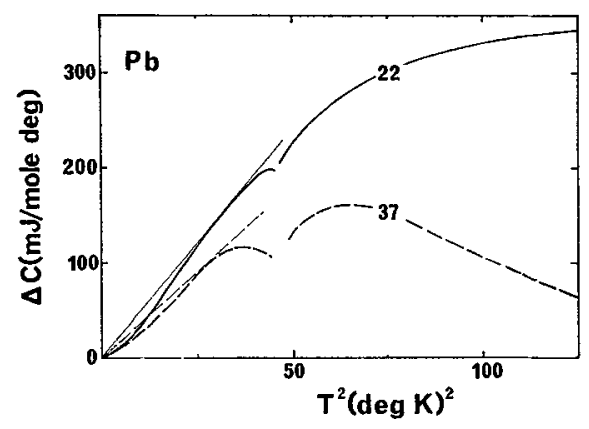

Fig. 1. - Measured specific heat enhancement $\Delta C=C_{\text {particle }}-C_{\text {bulk }}$ as a function of $T^{2}$ for lead particles of $22 \AA$ and $37 \AA$ average diameter (adapted from Ref. [113]). The non-quadratic behaviour for $T \leqslant 5 \mathrm{~K}<T_{\mathrm{c}} \approx 7 \mathrm{~K}$ is adscribed to the acoustical phonon quantum size effect $[66,68]$.

3. Optical phonons. - Since excellent reviews $[73,74,125,127]$ are available, only a brief account of optical vibrational modes in small dielectric particles is given here. Neutron scattering experiments [116] reveal not only changes in the optical mode density, but also the existence of gap-modes with frequencies between those of the 
acoustical and those of the optical bulk bands. The infrared absorption [117-125] and emission [126, 127] of small ionic crystal particles has been measured extensively. The theory of the corresponding polariton modes was likewise studied in detail [69-77, 136, 137].

The theoretical methods are similar to those used by Mie [1] and Debye [2] for the plasma modes and optical properties of metal spheres. Fröhlich [7] predicted a uniform optical vibrational mode of the frequency

$$
\omega_{\mathrm{S}}=\omega_{\mathrm{TO}}\left[\frac{\varepsilon_{0}+2}{\varepsilon_{\infty}+2}\right]^{1 / 2}=\left[\frac{1}{2}\left(\omega_{\mathrm{TO}}^{2}+\omega_{\mathrm{LO}}^{2}\right)\right]^{1 / 2}
$$

for small spheres (radius $R \ll \lambda_{\mathrm{TO}}=2 \pi c / \omega_{\mathrm{TO}}$ ) of diatomic ionic crystal material. Here, $\varepsilon_{0}$ and $\varepsilon_{\infty}$ denote the static, and high frequency dielectric constants, and $\omega_{\text {ro }}$ and $\omega_{\text {LO }}$ stand for the transverse-optical and longitudinal-optical bulk frequencies. Englman and Ruppin [69, 70] developed the correct theory of long-wave optical phonons in small spheres $\left(R \ll \lambda_{\mathrm{TO}}\right)$. Besides $\omega_{\mathrm{TO}}$ and $\omega_{\mathrm{LO}}$, they find a set of modes with frequencies

$$
\omega_{\mathrm{S} l}=\left\{\frac{1}{2 l+1}\left[(l+1) \omega_{\mathrm{TO}}^{2}+l \omega_{\mathrm{LO}}^{2}\right]\right\}^{1 / 2} .
$$

The case $l=1$ corresponds to a uniform mode of the type predicted by Fröhlich, whereas the cases $l \geqq 2$ correspond to modes that are localized near the surface. The frequency (15) is obtained in the limit $l \rightarrow \infty$. The theory for diatomic spheres of arbitrary size (i.e. accounting for the retardation of Coulomb forces) is due to Fuchs and Kliewer [71]. They find the following spectrum :

(i) The longitudinal mode with $\omega=\omega_{\text {LO }}$ as in bulk material.

(ii) High-frequency $\left(\omega>\omega_{\mathrm{LO}}\right)$ transverse modes with $\omega \rightarrow \infty$ for $R \ll \lambda_{\text {TO }}$ and $\omega \rightarrow \omega_{\text {LO }}$ for $R \geqslant \lambda_{\text {TO }}$.

(iii) Low-frequency $\left(\omega<\omega_{\mathrm{TO}}\right)$ transverse modes with $\omega \rightarrow \omega_{\text {TO }}$ for $R \ll \lambda_{\text {TO }}$ and $\omega \rightarrow 0$ for $R \gg \lambda_{\text {TO }}$.

(iv) Intermediate transverse modes with $\omega \rightarrow \omega_{\mathrm{S}}$ as given by (15) for $R \ll \lambda_{\text {TO }}$ and $\omega \rightarrow 0$ for $R \gg \lambda_{\text {TO }}$.

The same authors calculate the infrared absorption cross section and predict that only the mode

$$
\omega_{\mathrm{Si}}=\left[\frac{2}{3} \omega_{\mathrm{TO}}^{2}+\frac{1}{3} \omega_{\mathrm{LO}}^{2}\right]^{1 / 2}
$$

should be observed as an absorption (or emission) peak in the case $R \ll \lambda_{\text {To }}$.

A dominant gap mode (between $\omega_{\text {TO }}$ and $\omega_{\text {LO }}$ ) is indeed observed for small (diameter $d \approx 1-3 \mu \mathrm{m}$ ) crystals (see Fig. 2). The secondary peak near $\omega_{\text {To }}$ is adscribed to clustering effects [127]. The more involved theory of the optical properties of layers of crystal cubes has been studied as well [75-77, 127] and predicts secondary absorption peaks above the (slightly shifted) dominant gap mode frequency.
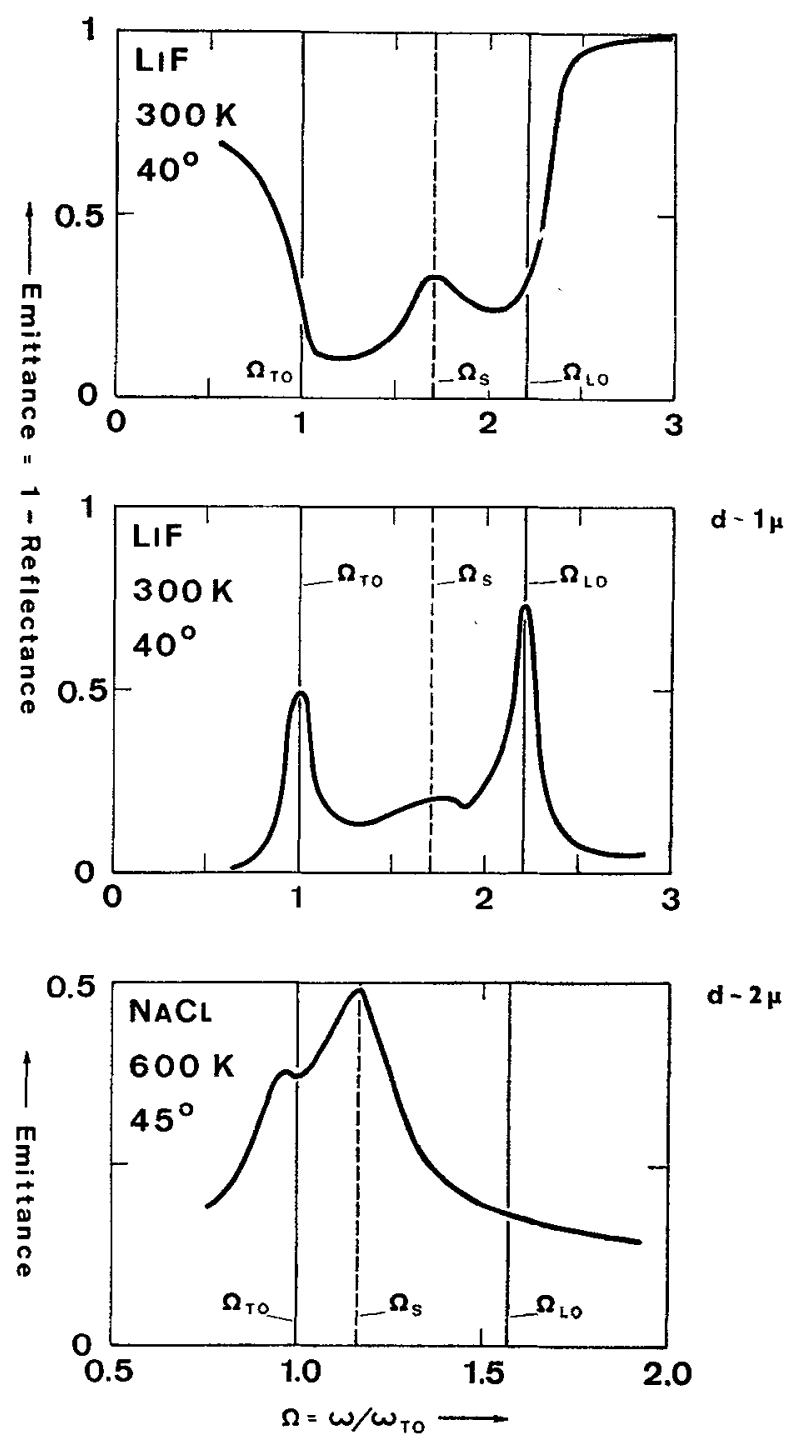

FIG. 2. - Infrared emittance of alkalihalide crystals as a function of the reduced frequency $\Omega=\omega / \omega_{\mathrm{TO}}$. A layer of cube-shaped particles (below, adapted from Ref. [126]) is compared with a thin slab (middle) and a bulk (above) crystal. Materials, temperatures, and average angles as well as $\Omega_{\text {ro }} \equiv 1$, $\Omega_{\mathrm{LO}}=\omega_{\mathrm{LO}} / \omega_{\mathrm{rO}}$, and $\Omega_{\mathrm{S}}=\left[1 / 2+\Omega_{\mathrm{LO}} / 2\right]^{1 / 2}$ are indicated. The bulk and slab surves are adapted from reflectance measuréthents of the type described in Ref. [138] and [139].

This kind of behaviour was observed recently [127].

Acknowledgments. - The present review was suggested by Pr. J. P. Borel, EPF Lausanne. The author would like to thank Dr. R. Kälin, ETH Zürich, and Dr. K. Schürmann, Landis \& Gyr Zug, for helpful discussions and valuable literature hints.

Note added in proof. - Recent measurements of the low-temperature vibrational specific heat of ultrafine palladium particles by $G$. H. Comsa, D. Heitkamp, and H. S. Räde [to appear in Solid State Commun. 1977] are in agreement with the BoseEinstein summation (2) or (14) of the vibrational modes as proposed by Baltes and Hilf [66]. 


\section{References}

[1] Mie, G., Ann. Phys. 25 (1908) 377.

[2] Debye, P., Ann. Phys. 30 (1909) 57.

[3] PLANCK, M., Theorie der Wärmestrahlung, 4th edition (J. A. Barth, Leipzig) 1921, p. 218.

[4] SChaEfer, C., Z. Phys. 7 (1921) 287.

[5] Froehlich, H., Physica 4 (1937) 406.

[6] Gialueue, W. F., ARchibald, R. C., J. Am. chem. Soc. 59 (1937) 561

[7] Froenlich, H., Theory of Dielectrics (Oxford University Press, London) 1949, p. 149.

[8] Montroll, E. W., J. Chem. Phys. 18 (1950) 183.

[9] Ebert, R., Hilf, E., J. Phys. Soc. Japan 26 (1969) 307.

[10] HILF, E., Z. Naturforsch. 25a (1970) 1190.

[11] Nenciu, G., J. Statist. Phys. 7 (1973) 119.

[12] Pathria, R. K., Phys. Rev. A 5 (1972) 1451.

[13] GReENSPOON, S., PATHRIA, R. K., Phys. Rev. A 8 (1973) 2657, A 9 (1974) 2103, and A 11 (1975) 1080.

[14] Baltes, H. P., Steinle, B., Pabst, M., Phys. Rev. A 13 (1976) 1866.

[15] Case, K., Chiu, S. C., Phys. Rev. A 1 (1970) 1170.

[16] Baltes, H. P., Kneubuehl, F. K., Opt. Commun. 4 (1971) 9, and Helv. Phys. Acta 45 (1972) 481

[17] Balian, R., Bloch, C., Ann. Phys. 64 (1971) 271.

[18] Baltes, H. P., Phys. Rev. A 6 (1972) 2252, Appl. Phys. 1 (1973) 208, Physica 67 (1973) 238.

[19] Baltes, H.P., Hilf, E. R., Comput. Phys. Commun. 3 (1972) 208

[20] Baltes, H. P., Hilf, E. R., Pabst, M., Appl. Phys. 3 (1974) 21.

[21] Steinle, B., Baltes, H. P., Pabst, M., Phys. Rev. A 12 (1975) 1519.

[22] AgarWal, G. S., Phys. Rev. A 11 (1975) 230, 245 and 253 ; A 12 (1975) 1475 and 1974.

[23] Eckhardt, W., Opt. Commun 14 (1975) 95 ; Z. Phys. B 23 (1976) 213.

[24] Polder, D., Van Hove, M., Phys. Rev. B 4 (1971) 3303.

[25] BOYER, T., Phys. Rev. 174 (1968) 1613 and 1764.

[26] Lukosz, W., Physica 56 (1971) 109 ; Z. Phys. 258 (1973) 99 and 262 (1973) 327.

[27] Wigner, E. P., Ann. Math. Stat. 53 (1951) 36 and 62 (1955) 548

[28] Dyson, F. J., J. Math. Phys. (N.Y.) 3 (1962) 140, 157, and 166.

[29] Dyson, F. J., Mehta, M. L., J. Math. Phys. (N.Y.) 4 (1963) $701,713$.

[30] MYERs, W. D., SWIATECKI, W. J., Nucl. Phys. 81 (1966) 1 ; Ark. Fys. 36 (1967) 343.

[31] Von Groote, H., Hilf, E. R., Nucl. Phys. A 129 (1969) 513.

[32] Balian, R., Bloch, C., Ann. Phys. 60 (1970) 401.

[33] Strutinski, V. M., Nucl. Phys. A 95 (1967) 420.

[34] Balian, R., Bloch, C., Ann. Phys. 69 (1972) 76.

[35] Brack, M., Damgaard, J., Jensen, A. S., Paul, H. C., Strutinski, V. M., Wong, C. Y., Rev. Mod. Phys. 44 (1972) 320.

[36] KubO, R., J. Phys. Soc. Japan 17 (1962) 975.

[37] Denton, R., MuEHrschlegel, B., SCAlapino, D. J., Phys. Rev. Lett. 26 (1971) 707 ; Phys. Rev. B 7 (1973) 3589.

[38] VAN GELDER, A. P., preprint.

[39] Gorkov, L. P., Eliashberg, G. M., Sov. Phys. J.E.T.P. 21 (1965) 940.

[40] Kawabata, A., Kubo, R., J. Phys. Soc. Japan 21 (1966) 1765.

[41] Straessler, S., Rice, M. J., Wyder, P., Phys. Rev. B 6 (1972) 2575.

[42] CarazzA, B., RazzeTrI, C., Lett. Nuovo Cimento 6 (1973) 250.

[43] Rice, M. J., Schneider, W. R., Straessler, S., Phys. Rev. 28B (1973) 474.

[44] Lushinov, A. A., Simonov, A. J., Z. Phys. 270 (1974) 17.
[45] Cini, M., Ascarelli, P., J. Phys. F : Metal Phys. 4 (1974) 1998.

[46] GreEnwood, D. A., Krumhansl, J. A., (1960) unpublished.

[47] Kawabata, A., J. Phys. Soc. Japan 29 (1970) 902.

[48] KNIGHT, W. D., J. Vac. Sci. Technol. 10 (1973) 705.

[49] Š́máneK, E., Maclaughlin, D. E., Imbro, D., preprint (1973).

[50] Stratton, R., Philos. Mag. 44 (1953) $519 ;$ J. Chem. Phys. 37 (1962) 2972.

[51] Dupuis, M., Mazo, R., Onsager, L., J. Chem. Phys. 33 (1960) 1452.

[52] Maradudin, A. A., Wallis, R. F., Phys. Rev. 148 (1966) 945.

[53] IosileVSkII, YA. A., Phys. Status Solidi (b) 46 (1971) 125 ; 44 (1971) $513 ; 53$ (1972) $405 ; 60$ (1973) 39.

[54] BURT, M. G., J. Phys. C: Solid State Physics 6 (1973) 855.

[55] Naugle, D. G., Alen, R. E., J. Chem. Phys. 63 (1975) 991.

[56] Allen, R. E., Alldredge, G. P., De Wette, F. W., Phys. Rev. B 4 (1971) 1648, 1661, and 1682; B 6 (1972) 632.

[57] Chen, T. S., Alldredge, G. P., De Wette, F. W., Allen, R. E., Phys. Rev. B 6 (1972) 627.

[58] Thoma, K., Zimmermann, R., Z. Phys. 252 (1972) 168.

[59] Wallis, R. F., Cheng, D. J., Solid State Commun. 11 (1972) 221.

[60] Maradudin, A. A., Mills, D. C., Appl. Phys. Lett. 28 (1976) 573.

[61] DE WETTE, F. W., Alldredge, G. P., Lattice dynamics of surfaces of solids, in : Vibrational Properties of Solids, ed. by Gilat, G. (Academic Press, New York) 1976.

[62] Masri, P., J. Phys. 35 (1974) 433.

[63] Maradudin, A. A., Wallis, R. F., Mills, D. L., BalLARD, R. L., Phys. Rev. B 6 (1972) 1106.

[64] Moss, S. L., Maradudin, A. A., Cunningham, S. L., Phys. Rev. B 8 (1973) 2999.

[65] Jura, G., Pitzer, K.S., J. Am. Chem. Soc. 74 (1952) 6030.

[66] Baltes, H. P., Hilf, E. R., Solid State Commun. 12 (1973) 369.

[67] NonNENMACHER, Th., Phys. Lett. 51A (1975) 213.

[68] Lautenschlaeger, R., Solid State Commun. 16 (1975) 1331.

[69] Englman, R., Ruppin, R., Phys. Rev. Lett. 16 (1966) 898 ; J. Phys. G (Proc. Roy. Soc.) 1 (1968) 614 and 1515.

[70] Ruppin, T., Englman, R., J. Phys. C: Solid State Physics 1 (1968) 630.

[71] Fuchs, R., Kliewer, K. L., J. Opt. Soc. Am. 58 (1968) 319.

[72] RÙPPIN, R., Surf. Sci. 34 (1973) 20.

[73] Ruppin, R., Englana, R., Rep. Prog. Phys. 33 (1970) 149.

[74] Klinwer, K. L., FuCHS, R., Adv. Chem. Phys. 27 (1974) 355.

[75] Van Gelder, A. P., Holvast, J., Stoelinga, J. H. M., Wyder, P., J. Phys. C: Solid State Physics 5 (1972) 2757.

[76] Fuchs, R., Phys. Lett. 48A (1974) 353 ; Phys. Rev. B 11 (1975) 1732.

[77] Langbein, D., J. Phys. A : Math. Nucl. Gen. 9 (1976) 627.

[78] Thomas, H., Z. Angew. Phys. 15 (1963) 201.

[79] AbBEL, R., Z. Angew. Phys. 20 (1966) 212.

[80] Ritchie, D. S., Fisher, M. E., Phys. Rev. B 7 (1973) 480.

[81] BInder, K., Physica 62 (1972) 508.

[82] Dомв, C., J. Phys. A : Math. Nucl. Gen. 6 (1973) 1296.

[83] Hurault, J. P., Maki, K., Beal-Monod, M. T., Phys. Rev. B 3 (1971) 762.

[84] Muehlschlegel, B., Scalapino, D. J., Denton, R., Phys. Rev. B 5 (1972) 1767.

[85] Takayama, H., Prog. Theor. Phys. 48 (1972) 382 and 758.

[86] Gunther, L., Deutscher, G., Imry, Y., Phys. Rev. B 7 (1973) 3393.

[87] DeUTSCher, G. and ImRY, Y., Phys. Lett. 42 (1973) 413. 
[88] Deutscher, G., Gershenson, M., Gruenbaum, E., Imry, Y., J. Vac. Sci. Technol. 10 (1973) 697.

[89] Deutscher, G., Imry, Y., Gunther, L., Phys. Rev. B 10 (1974) 4598.

[90] Drexhage, K. H., Prog. Opt. 12 (1974) 165.

[91] Hargreaves, C. M., Proefschrift, Univ. Leiden (1973).

[92] Kunklinger, S., Dissertation Techn. Hochschule München (1969)

[93] Ludwig, S., Von Groote, H., Hilf, E., Nucl. Phys. A 203 (1973) 627.

[94] Nix, J. R., Ann. Rev. Nucl. Sci., 22 (1972) 65

[95] Meier, F., Wyder, P., Phys. Rev. Lett. 30 (1973) 181.

[96] Kobayashi, S., Takahashi, T., Sasaki, W., J. Phys. Soc. Japan 31 (1971) $1442 ; 32$ (1972) 1234 and 1668.

[97] Dupree, R., Smithard, M. A., J. Phys. C: Solid State Physics 5 (1972) 408.

[98] MEIER, F., WYDER, P., Phys. Lett. 39A (1972) 51.

[99] Kreibig, V., V. Fragstein, C., Z. Phys. 224 (1969) 307.

[100] Smithard, M. A., DUPree, R., Phys. Status Solidi (a) 11 (1972) 695.

[101] Smithard, M. A., Tran, M. Q., Helv. Phys. Acta 46 (1974) 869.

[102] Smithard, M. A., Solid State Commun. 14 (1974) 407.

[103] Tanner, D. B., Sievers, A. J., Buhrman, R. A., Phys. Rev. B 11 (1975) 1330.

[104] Granqvist, C. G., Buhrman, R. A., Wyns, J., Sievers, A. J., Phys. Rev. Lett. 37 (1976) 625.

[105] Taupin, C., J. Phys. Chem. Solids 28 (1967) 41.

[106] Kobayashi, S., Takahashi, T., Sasaki, W., Phys. Lett. 33A (1970) 429.

[107] MONot, R., Châtelain, A., Borel, J.-P., Phys. Lett. 34A (1971) 1 and 57.

[108] Smithard, M. A., Solid State Commun. 13 (1973) 153.

[109] Monot, R., NARbel, C., Borel, J.-P., Nuovo Cimento B 19 (1974) 253.

[110] Chátelain, A., Millet, J.-L., Monot, R., J. Appl. Phys. 47 (1976) 3670.

[111] Abeles, B., Ping Sheng, Coutts, M. D., ArIe, Y., Adv. Phys. 24 (1975) 407.

[112] Novotny, V., Meincke, P. P. M., Watson, J. H. P. Phys. Rev. Lett. 28 (1972) 901.

[113] Novotny, V., Meincke, P. P. M., Phys. Rev. B 8 (1973) 4186.

[114] Maradudin, A. A., Solid State Phys. 19 (1966) 1, chap. IV.
[115] Akselrod, S., Pasterñak, M., Bukshpan, S., Phys. Rev. B 11 (1975) 1040.

[116] Rieder, K. H., Surf. Sci. 26 (1971) 637; Phys. Rev. Lett. 34 (1975) 148.

[117] BRYSkin, V. V., GERBSTEIN, YU. M., MiRLiN, D. N., Sov. Phys. Solid State 13 (1971) 1342 ; Solid State Commun. 9 (1971) 669.

[118] Martin, T. P., Phys. Rev. 177 (1969) 1349; Solid State Commun. 9 (1971) 623 ; Phys. Rev. B 8 (1973) 3480.

[119] Steyer, T. R., Day, K. L., Huffman, D. R., Appl. Opt. 13 (1974) 1586

[120] Luxon, J. T., Montgomery, D. J., Summit, R., Phys. Rev. 188 (1969) 1345 ; J. Appl. Phys. 41 (1970) 2303.

[121] Novàk, L., Solid State Commun, 9 (1971) 2129; Phys. Status Solidi (b) 56 (1973) 307.

[122] PastrŃak, J., Vedam, K., Phys. Status Solidi (a) 3 (1970) 647.

[123] Nahum, J., Ruppin R., Phys. Status Solidi (a) 16 (1973) 459.

[124] Genzel, L., Martin, T. P., Phys. Status Solidi (b) 51 (1972) 91 ; Surf. Sci. 34 (1973) 33.

[125] GENZEL, L., Festkörperprobleme 14 (1974) 183

[126] Kaelin, R., Baltes,.H. P., KNeUbUehl, F. K., Helv. Phys. Acta 43 (1970) 487 ; Solid State Commun. 8 (1970) 1495.

[127] Kaelin, R., Kneubuehl, F. K., Infra. Phys. 16 (1976) 491.

[128] PIUz, F., Borel, J.-P., Phys. Status Solidi (a) 14 (1972) 129.

[129] Buffat, Ph., Borel, J.-P., Phys. Rev, A 13 (1976) 2287.

[130] Baltes, H. P., Infra. Phys. 16 (1976) 1.

[131] Baltes, H. P., Appl. Phys., to be published.

[132] BALTES, H. P., HrLF, E. R., Spectra of Finite Systems (Bibliographisches Institut, Zürich) 1976.

[133] DeBYe, P., Ann. Phys. (Leipzig) 39 (1912) 789.

[134] WEYL, H., Rend. Circ. Mat. Palermo 39 (1915) 1.

[135] Benson, G. C., YUN, K. S., in : The solid-gas interface, ed. by Flood, E. A. (Marcel Dekker, New York) 1967.

[136] Genzel, L., Martin, T. P., Phys. Status Solidi (b) 51 (1972) 101

[137] Martin, T. P., Phys. Rev. B 7 (1973) 3906.

[138] Jasperse, J. R., Kahan, A., Plendl, J. N., Mrtra, S. S., Phys. Rev. 146 (1966) 526.

[139] Berremann, D. W., Phys. Rev. 130 (1963) 2193. 